\title{
VARIABILIDAD EN LA EXPLOTACIÓN Y PROCESAMIENTO DE UNGULADOS EN EL SECTOR CENTRO-ORIENTAL DE LA REGIÓN PAMPEANA
}

\author{
VARIABILITY IN THE EXPLOITATION AND PROCESSING OF \\ UNGULATES IN THE EASTERN CENTRAL REGION OF THE PAMPEAN \\ REGION
}

\author{
Alejandro Acosta ${ }^{1}$, Daniel Loponte ${ }^{2}$ y Leonardo Mucciolo ${ }^{3}$ \\ 1. CONICET-Instituto Nacional de Antropología y Pensamiento Latinoamericano (INAPL) 3 de Febrero 1378 \\ C1426BJN, CABA. E-Mail: acosta@retina.ar \\ 2. CONICET-Instituto Nacional de Antropología y Pensamiento Latinoamericano (INAPL) 3 de Febrero 1378 \\ C1426BJN, CABA. E-Mail: leonardomucciolo@yahoo.com.ar \\ 3. CONICET-Instituto Nacional de Antropología y Pensamiento Latinoamericano (INAPL) 3 de Febrero 1378 \\ C1426BJN, CABA. E-Mail: leonardomucciolo@yahoo.com.ar
}

Presentado el: 08/10/2013 - Aceptado 25/06/2013

\section{Resumen}

Se analiza la explotación de ungulados por parte de los grupos cazadores-recolectores que ocuparon el sector centro-oriental de la región Pampeana durante la fase final del Holoceno tardío ( $<2000$ años AP). Para ello, consideramos las características eto-ecológicas de los principales taxa explotados (Lama guanicoe, Blastocerus dichotomus y Ozotoceros bezoarticus) y comparamos la información arqueofaunistica procedente de dos sitios arqueológicos situados en dos de las unidades del paisaje que integran la región bajo estudio. A partir de los resultados obtenidos, mediante la aplicación de diferentes indices, se postulan distintas hipótesis con el fin de establecer y discutir similitudes y diferencias relacionadas con la importancia económica que adquirieron dichas presas y las modalidades utilizadas para su procesamiento y consumo.

Palabras claves: Cazadores-recolectores, ungulados, Holoceno tardio, Región Pampeana

\footnotetext{
Abstract

This paper analyze ungulate exploitation by hunter-gatherer groups which inhabited enter-east Pampean region during the Late Holocene $(<2000$ years BP). For this purpose we consider the eto-ecological conditions of the main exploited taxa (Lama guanicoe, Blastocerus dichotomus
} 
and Ozotoceros bezoarticus) and the archaeofaunal information of two archaeological sites located in different landscape units of the region under study. On the basis of the obtained results, applying multiple indices, we propose different hypotheses to discuss similarities and differences linked to the economic importance of different preys and their consumption and processing techniques.

Keywords: Hunter-gatherer, ungulates, Late Holocene, Pampean region

\section{Introducción}

El objetivo de este trabajo consiste en analizar la explotación diferencial de ungulados y la variabilidad arqueológica resultante generada por los grupos cazadores-recolectores que ocuparon el sector centro-oriental de la región Pampeana (en adelante SCORP) durante el Holoceno tardío. Para ello se analiza y compara el registro faunístico de ungulados recuperado en dos sitios ubicados en dos unidades diferentes del paisaje que integran la región bajo estudio (ver figura 1 ).

El SCORP presenta un significativo contraste ambiental en su extremo nordeste, dado que se articulan distintas áreas o unidades de paisaje con marcadas diferencias ecológicas (Cabrera 1958, Bonfils 1962, Cabrera y Willink 1980, Burkart et al. 1999). La primera unidad está constituida por una llanura bien drenada, con una cota promedio de $30 \mathrm{msnm}$, denominada Pampa Ondulada (PO, Daus 1946). La segunda unidad está compuesta por los denominados Bajíos Ribereños (BR, Bonfils 1962), integrada por una estrecha llanura de inundación del sistema fluvial Paraná-Plata, que posee una cota promedio de $2 \mathrm{msnm}$. Ecológicamente está regulada por los pulsos cálidos del río Paraná, que ha generado un ambiente de humedal continental de características subtropicales que integra parte del humedal del Paraná inferior (HPI) (cf. Loponte 2008). La línea de contacto entre ambas es un paleoacantilado generado durante la ingresión marina del Holoceno (Cavallotto et al. 2004), sobre el cual se desarrolla, en forma variable, una estrecha cuña de bosque xeromórfico (Cabrera y Zardini 1978).

Las diferencias ecológicas, así como la oferta diferencial de recursos y la expectativa arqueológica derivada fue motivo de un modelo publicado en los comienzos de 1990 ( $c f$. Loponte et al. 1991). Dicho modelo era esencialmente predictivo, ya que en aquel entonces era muy pocos los depósitos arqueológicos excavados. El único registro conocido de la PO correspondía al sitio Cañada de Rocha, excavado en el siglo XIX (Ameghino 1947 [1880]). Por otro lado, los datos disponibles para el HPI era aún fragmentarios y el nivel de excavación y análisis de los mismos se encontraba en una etapa inicial. La continuidad de las investigaciones, desde la década del 90 hasta la actualidad, posibilitó no solo avanzar en el monitoreo de las hipótesis inicialmente propuestas, sino también en profundizar ciertos aspectos de las mismas y generar nuevas preguntas mediante diferentes análisis y a partir de una base empírica mucho más sólida producto de la localización, excavación y análisis sistemático de diversos sitios ubicados en diferentes puntos del HPI (e.g. Loponte 2008, Acosta et al. 2010a y b, Arrizurieta et al. 2010a, Loponte et al. 2012).

En cuanto a la PO, recientemente se localizaron y excavaron dos nuevos sitios arqueológicos: Hunter y Meguay (Loponte et al. 2010). La información arqueológica obtenida indica la existencia de cazadores-recolectores con una organización económica y tecnológica diferente respecto de la generada por los grupos humanos que habitaron el HPI. Una de las diferencias observadas, que aquí evaluaremos en detalle, radica justamente 


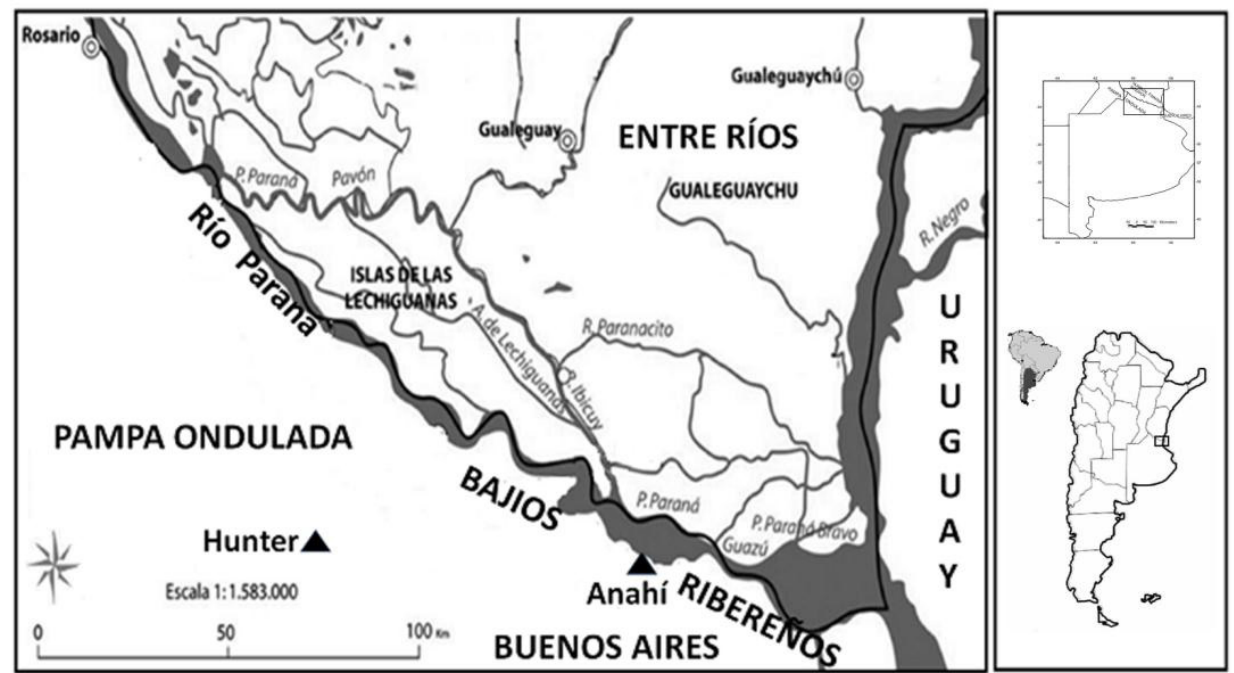

Figura 1. Ubicación de las dos áreas (Bajíos ribereños y Pampa Ondulada) y localización aproximada de los sitios (Anahí y Hunter) de donde proceden las muestras arqueofaunísticas que aquí se estudian.

en la importancia relativa que tuvieron económicamente los ungulados y las estrategias de explotación implementadas por ambas poblaciones de cazadores-recolectores. Algunos aspectos particulares relacionados con este tópico ya han sido tratados en otros trabajos (Loponte 1996-98, Loponte et al. 2004, Acosta 2005, Loponte 2008, Mucciolo 2010). Aquí nos proponemos aportar nuevos datos concurrentes, con el fin de comparar y discutir distintas propiedades relacionadas con las estrategias de acarreo, procesamiento y consumo y el grado de intensificación económica al que habrían sido sometidos los ungulados en las áreas de estudio mencionadas (Bajíos Ribereños y Pampa Ondulada).

Para efectuar las comparaciones, utilizaremos la colección faunística del sitio Hunter (PO), procedente de la subunidad D1 y la base de la subunidad D2, cuya antigüedad fue fijada en $1990 \pm 40$ años $C^{14} \mathrm{AP}$ (Loponte et al. 2010), mientras que para el sector de BR emplearemos datos provenientes del sitio Anahí fechado en $1020 \pm 70$ años $\mathrm{C}^{14} \mathrm{AP}$ (Loponte 2008). Los depósitos de ambas unidades del paisaje son funcionalmente asimilables a bases residenciales (sensu Binford 1980). Las diferencias que observamos, entonces, no se deben a una función específica de los sitios, sino que representan parte de la variabilidad de las estrategias de subsistencia desarrolladas en las distintas unidades del paisaje y conforman parte de la diferencias de la estructura del registro regional.

\section{Los ungulados del sector centro-oriental de la región Pampeana}

En este acápite efectuamos una breve síntesis sobre las principales características que tuvieron las tres especies de ungulados de mayor importancia que habitaron la región bajo estudio: guanaco, venado de las pampas y ciervo de los pantanos.

El guanaco es el mayor de los camélidos silvestres que se conocen en Sudamérica, su masa corporal oscila entre los 70 y los $120 \mathrm{~kg}$, aspecto que se correlaciona con su distribución latitudinal. Es una especie que presenta una amplia distribución geográfica y posee una serie de rasgos (anatómicos y fisiológicos) que le otorgan una alta y flexible capacidad de adaptación ya que ha sido, actual e históricamente, registrada en una 
variada gama de ambientes, desde el extremo sur de Patagonia hasta el occidente de la República del Paraguay y del centro-norte de Sudamérica (Franklin 1981, Bonavía 1996, Redford y Eisenberg 1996). El ciervo de los pantanos es el cérvido autóctono de mayor tamaño de América del Sur. Los machos adultos pueden alcanzar un peso de hasta $150 \mathrm{~kg}$ (Pinder y Grosse 1991); actualmente se encuentra amenazado y su distribución original se habría reducido en un 65 \% (Weber y González 2003). Habita fundamentalmente en ambientes subtropicales con extensos humedales, como los que se desarrollan en distintas regiones del sur del Amazonas y del NE de Argentina en donde aún persisten importantes relictos poblacionales de este mamífero (Duarte et al. 2008). Durante el Holoceno tardío rebasó el área de estudio a lo largo del estuario del Río de la Plata y alcanzó el sur de la Bahía de San Borombón (Loponte y Corriale 2012). El venado de las pampas es un cérvido de mediano tamaño (Dellafiore et al. 2001) y su peso oscila entre los 25 y $35 \mathrm{~kg}$. Si bien en la actualidad es una especie protegida, dado que se encuentra en franca retracción numérica, históricamente tuvo una amplia distribución en el subcontinente (parte de Brasil, Bolivia, Paraguay, Argentina y Uruguay) especialmente en aquellas regiones que poseen llanuras abiertas con escasa vegetación arbórea (Cabrera y Yepes 1960).

Dados los requerimientos ecológicos y las preferencias de hábitat que poseen el guanaco y el venado, durante el Holoceno ambas especies estuvieron disponibles en la Pampa Ondulada, con una distribución parcialmente superpuesta. Esta misma situación habría ocurrido en otras áreas de la llanura pampeana, tal como lo indica la simple y recurrente presencia que existe de ambas especies a lo largo de casi todo el Holoceno en distintos sitios y conjuntos arqueofaunísticos (e.g. Martínez y Gutiérrez 2004). En relación al guanaco debe mencionarse que habría estado disponible en la PO como mínimo hasta el siglo XV AD (Toledo 2010), y que su retracción coincide con la invasión biológica de los mamíferos exóticos (Loponte 1996/98, Loponte 2008, Loponte y Acosta en prep.). Cabe agregar que dicha especie también pudo estar eventualmente presente en el interior del bosque xeromórfico y/o en los bordes de la estepa pampeana adyacente al mismo, situación similar a la que actualmente sucede en otras regiones de la Argentina como, por ejemplo, en la Isla de Grande de Tierra del Fuego (e.g. Montes et al. 2000).

Por otra parte, sabemos que el venado de las pampas ocupa generalmente llanuras altas y abiertas, aunque también puede incursionar y/o habitar zonas medianamente bajas e inundables (como los BR), como así también ambientes boscosos (cf. Parera y Moreno 2000, Silva y Mauro 2002). En cuanto al ciervo de los pantanos, su hábitat es mucho más restringido, ya que es una especie típica de las zonas bajas y pantanosas propias del humedal del Paraná inferior (D`Alessio et al. 2001). En el HPI, esta presa habría estado disponible como mínimo desde la segunda mitad del III milenio, dado que ha sido registrada en por lo menos dos sitios arqueológicos de esta antigüedad (Islas Lechiguanas y Playa Mansa; Caggiano 1984, Acosta et al. 2011, Loponte et al. 2012).

\section{Metodología}

Para comparar los conjuntos arqueofaunísticos de ambas unidades del paisaje se aplicaron los índices de abundancia taxonómica (NISP, NMI) y anatómica (MNE, MAU y \%MAU) (Lyman 1994). La integridad tafonómica se evaluó mediante el análisis de las siguientes variables: estado de meteorización (sensu Behrensmeyer 1978), señales de abrasión hídrica y marcas de carnívoros y roedores (Binford 1981, Lyman 1994). Asimismo, se tuvieron 
en cuenta diversos aspectos relativos a la composición de los suelos y los posibles procesos diagenéticos implicados (ver más abajo). A fin de establecer si la preservación de los conjuntos óseos se hallaba o no mediada por la densidad mineral (DMO) se realizaron correlaciones (rho Spearman) entre los \%MAU y la DMO (Lam et al 1999, Stahl 1999).

Para evaluar si existió transporte selectivo de partes esqueletarias se efectuaron correlaciones entre los \% MAU y los índices de utilidad económica FUI y MUI (Metcalfe y Jones 1988, Borrero 1990). Se consideró la completitud global y por región anatómica (apendicular/axial) y el MNE estandarizado por subregión anatómica (cf. Stiner 1994; De Nigris 2004). Se relevó la presencia de huellas de procesamiento y negativos de lascado (Mengoni Goñalons 1999). Para evaluar la intensidad de procesamiento, se estimó el grado de fragmentación a través de la razón NISP:MNE ( $c f$. Lyman 1994) y se relevó la completitud de los cuerpos vertebrales y epífisis de huesos largos, así como las longitudes de estos últimos, incluyendo los fragmentos de diáfisis correspondientes a mamíferos medianos $(\mathrm{MM})$ y grandes (MG) que tuvieran una alta probabilidad de pertenecer a venado de las pampas en el caso de los primeros (MM) y a ciervo de los pantanos o guanaco, en el caso de los segundos (MG). Finalmente, como indicador del estado de los especímenes en el momento de su fractura, se aplicó el índice de fractura fresca (FFI, Fracture Freshness Index) propuesto por Outram $(2001,2002)$.

\section{Análisis de las muestras e interpretación de los resultados obtenidos}

\section{Integridad tafonómica y procesos de formación de los conjuntos óseos}

En la tabla 1 puede verse la incidencia que habrían tenido los distintos factores tafonómicos considerados. En general, se observa que los mismos no habrían comprometido sustancialmente la integridad de los conjuntos arqueofaunísticos de cada unidad de paisaje. La acción de carnívoros y de roedores es muy baja. La meteorización no supera los estadios 1-2 (sensu Behrensmeyer 1978). Sin embargo, en Hunter se han observado especímenes con signos leves de abrasión hídrica, aspecto que diferencia notoriamente ambos conjuntos. Finalmente, en ambos conjuntos las covariaciones efectuadas entre los \% MAU y la DMO indican que las muestras óseas no están mediadas por esta variable (ver tabla 2).

En Hunter se detectó una mayor cantidad de fracturas en estado seco que la registradas en Anahí (ver más abajo). En los trabajos de campo pudimos observar que los huesos hallados, si bien se encontraban bien conservados, varios de ellos presentaban pequeñas grietas o líneas de fisuras, posiblemente generadas por la presión sedimentaria, además de cierta debilidad estructural que los tornaba quebradizos durante su extracción. A ello hay que sumar la diferencia en el grado de abrasión hídrica de uno y otro conjunto (ver tabla 1). Esto sugiere

\begin{tabular}{|l|c|c|}
\hline \multicolumn{1}{|c|}{ Variable } & $\begin{array}{c}\text { Hunter } \\
\text { L. guanicoe }+ \text { O. bezoarticus }\end{array}$ & $\begin{array}{c}\text { Anahí } \\
\text { B. dichotomus }+ \text { O. bezoarticus }\end{array}$ \\
\hline \%NISP con meteorización $\leq 2$ & 94,42 & 93,10 \\
\hline \%NISP con marcas de roedores & 1,32 & 0,28 \\
\hline \%NISP con marcas de carnívoros & 0,19 & 0,06 \\
\hline $\begin{array}{l}\text { \%NISP con marcas de abrasión } \\
\text { hídrica }\end{array}$ & 60,70 & 0,0 \\
\hline
\end{tabular}

Tabla 1. Principales agentes tafonómicos relevados en los sitios Hunter y Anahí. 


\begin{tabular}{|c|c|c|c|c|c|c|c|}
\hline \multicolumn{4}{|c|}{ HUNTER } & \multicolumn{4}{|c|}{ ANAHÍ } \\
\hline \multicolumn{4}{|c|}{ L. guanicoe } & \multicolumn{4}{|c|}{ B. dichotomus } \\
\hline Correlación & rs & $p$ & $\mathrm{NC}$ & Correlación & rs & $p$ & $\mathrm{NC}$ \\
\hline MAU-MUI & 0,59 & $>0,05$ & 18 & MAU-MUI & 0,10 & $>0,05$ & 31 \\
\hline MAU-DMO & 0,65 & $>0,05$ & 45 & MAU-DMO & 0,05 & $>0,05$ & 41 \\
\hline \multicolumn{8}{|c|}{ O. bezoarticus } \\
\hline Correlación & $r_{S}$ & $p$ & $\mathrm{NC}$ & Correlación & $r_{S}$ & $\mathrm{p}$ & $\mathrm{NC}$ \\
\hline MAU-MGUI & 0,23 & $>0,05$ & $28^{*}$ & MAU-MGUI & 0,02 & $>0,05$ & 30 \\
\hline MAU-DMO & 0,01 & $>0,05$ & $40^{*}$ & MAU-DMO & 0,46 & $>0,05$ & 41 \\
\hline
\end{tabular}

Tabla 2. Correlaciones entre \%MAU, índices de utilidad y densidad mineral ósea (DMO). Referencias: $\mathrm{NC}=$ número de casos correlacionados.

que los elementos óseos de Hunter habrían tenido una historia diagenética diferente a la que tuvieron los recuperados en Anahí. En este sentido, sabemos que la pérdida de colágeno como la lixiviación, sustitución y/o enriquecimiento mineral de los huesos dependen de diversos procesos diagenéticos (cf. Nielsen-Marsh y Hedges 2000, Hedges 2002) que parecen haber impactado de manera distinta en cada conjunto óseo. La composición estructural de la matriz sedimentaria del depósito y su entorno constituyen parte de los aspectos involucrados en dichos procesos (Nielsen-Marsh y Hedges 1997). Se ha señalado que los restos óseos que provienen de depósitos fósiles situados en planicies aluviales inundables conformadas por sedimentos arenosos tienden a ser, generalmente, mucho más porosos y quebradizos ( $c f$. Hedges 2002). Esta podría ser la situación del conjunto óseo del sitio Hunter, el cual se hallaba originalmente situado sobre un paleocauce lateral al antiguo río Arrecifes (provincia de Buenos Aires). Análisis geoarqueológicos permitieron establecer que, para el momento de la ocupación que generó el depósito de las subunidades D1 y D2, la hondonada conformada por el paleocauce se encontraba adyacente al curso principal del río homónimo, razón por la que es posible que durante los eventos de inundación ambos paleocauces quedaran temporaria o esporádicamente conectados. El paleocauce en donde se ubica el sitio, a posteriori de la ocupación humana se sedimentó con el aporte de arenas finas arcillosas de color negro, con una elevada tasa de decantación de material fino. La bioturbación del estrato habría sido moderada y los procesos de pedogénesis se habrían desarrollado bajo condiciones oxidantes, tal como lo indica la ausencia de colores gley en los sedimentos (Tchilinguirian et al. 2011). Esto último sugiere que, si bien a lo largo de su historia sedimentaria el paleocauce pudo estar total o parcialmente anegado, esta situación no habría sido permanente sino más bien temporaria (ver detalles en Tchilinguirian et al. 2011), rasgo que pudo incidir en una diagénesis mucho más variable, tal como sucede en otros contextos en donde se han advertido significativas diferencias a nivel intradepósito ( $c f$. Hedges 2002, Farlow y Argast 2006). El sitio se habría sedimentado en un ambiente de muy baja energía hídrica y si bien esta presunción se basa fundamentalmente en estudios geoarqueológicos, también se ve sustentada por la alta presencia de elementos óseos de guanaco que poseen un alto índice de flotabilidad, correspondientes a los grupos I y II de Voorhies (1969) (Tchilinguirian et al. 2011), como así también por numerosas placas dérmicas de dasipódidos que son muy livianas (Loponte y Acosta 2012). En Hunter, además, no deben descartarse posibles episodios de erosión y resedimentación, considerando que se identificó una fracción de huesos diferencialmente coloreados y levemente abradidos. 
Por otra parte, en ambientes con suelos inundables y parcialmente saturados, los efectos de la acción microbiana sobre los restos óseos es menos destructiva (Nielsen-Marsh y Hedges 2000, Hedges 2002), pero el contenido mineral del agua y de los suelos, sumado al tipo de $\mathrm{pH}$, son factores que pueden incidir en su preservación diferencial (Hedges y Millard 1995, Hedges 2002). Los suelos de la Pampa Ondulada, en donde de ubica el sitio Hunter, se caracterizan por ser ligera a fuertemente alcalinos ( $\mathrm{pH}$ en agua $=8$ a 8.7), condición que habría favorecido la preservación de los restos óseos (e.g. Gordon y Buikstra 1981). Además, poseen un alto contenido de sodio, intercambiable entre 20 a 15 m.e/100 g (Etchevehere 1974). Si los conjuntos óseos recuperados en Hunter presentasen una alta tasa de sustitución de hidroxiapatita por el sodio, este factor, junto al entorno ambiental, podrían ser parte de los procesos involucrados en su debilidad estructural y, por ende, en la mayor presencia de fracturas en estado seco identificadas y generadas, posiblemente, por la presión sedimentaria. El bajo peso específico que poseen la mayoría de los huesos y su tonalidad parda blanquecina podría deberse en alguna medida a la pérdida de masa del suelo, el aumento de la porosidad y la cristalización del sodio y calcio que originan las fracturas del hueso por crecimiento secundario de sales (haloclastismo). Los análisis en curso (cortes histológicos y composición mineral) posibilitarán evaluar estos aspectos y obtener datos más precisos sobre la historia diagenética de los restos óseos recuperados en el sitio Hunter.

En el caso de los BR, a pesar de que todos los sitios también se encuentran en planicies inundables, la situación es diferente. Los cordones litorales con formación de suelos constituyen las geoformas típicas en donde localizan casi todos los depósitos arqueológicos de esta unidad ambiental. Se trata de topografías positivas, constituidas por elevaciones de origen fluvial, cuya altura y estructura sedimentaria es claramente distinta al resto del paisaje circundante. Los suelos que contienen al material arqueológico son los Molisoles, también denominados "suelos gley húmicos" (Bonfils 1962). En líneas generales, estos suelos se caracterizan por presentar un $\mathrm{pH}$ generalmente neutro (entre 6.8 a 7.5 ) y un alto contenido mineral compuesto fundamentalmente por hierro $(\mathrm{Fe})$ y manganeso $(\mathrm{Mg})$. La precipitación de Mg sobre el material óseo indica la descomposición de materia orgánica durante la fase más temprana de la diagénesis (Parker y Toots 1970). El intenso oscurecimiento, con graduaciones tonales que van del marrón al negro, que presentan los conjuntos óseos recuperados en Anahí y en la mayoría de los sitios que se encuentran en los BR constituye un indicador de este proceso. Asimismo, análisis semicuantitativos y densitométricos demostraron la transferencia de Fe y $\mathrm{Mg}$ desde los suelos hacia los huesos arqueológicos que muestran una notable incidencia tanto en el proceso de recristalización de los restos arqueofaunísticos como en el aumento de su peso específico (ver detalles en Acosta 2005, Loponte 2008), siendo esta última propiedad notoriamente superior a la registrada en el conjunto óseo de Hunter.

Independientemente de las diferencias señaladas, notamos que en general las muestras óseas procedentes de ambas áreas no experimentaron severos daños tafonómicos que hayan sesgado los índices de abundancia y representación; en consecuencia es posible considerar que los humanos fueron los principales agentes involucrados en su formación. Por lo tanto, la variabilidad e integridad diferencial que exhiben los conjuntos arqueofaunísticos estaría en buena medida relacionada con las estrategias utilizadas para el aprovechamiento de la fauna, aspectos que a continuación se plantean y discuten en función de las similitudes y diferencias que presentan los conjuntos óseos de ungulados en cada uno de los sitios y áreas estudiadas. 


\section{Variabilidad de los conjuntos óseos y estrategias de explotación de los ungulados}

Un primer aspecto general a considerar es la representación diferencial que, taxonómica y anatómicamente, poseen los ungulados explotados en las distintas áreas estudiadas. En relación a $O$. bezoarticus notamos que, si bien existen variaciones en su NMI, se encuentra presente en los sitios de los BR y en los de la PO. Además, exhibe una representación anatómica muy similar y señales diversas que avalan su procesamiento y consumo (ver Acosta 2005, Loponte 2008). Sus requerimientos ecológicos le permitieron distribuirse por ambos ambientes (PO y BR), lo que facilitó su encuentro dentro del rango de acción de los cazadores de ambos espacios, integrando su dieta.

La situación de los ungulados de mayor porte (B. dichotomus y L. guanicoe) es totalmente diferente. En principio porque no existen registros de B. dichotomus en los sitios de PO; pero en los BR y en casi todo el humedal del Paraná inferior constituyó una presa que está presente en todos los depósitos arqueológicos (ver Loponte 2008, Acosta et al. 2010a, Arrizurieta et al. 2010a, Loponte et al. 2012). A diferencia del primer taxón, L. guanicoe se encuentra, arqueológicamente, presente en ambas áreas; aunque en la PO el NMI y los perfiles anatómicos son sustancialmente distintos a los registrados en los sitios de los BR. En los depósitos situados en los BR ( $c f$. Loponte 2008) y en el área contigua del estuario intermedio del Río de la Plata (EIRP) (Paleo et al. 2002, Paleo y Pérez Meroni 2007), en la mayoría de los casos su número mínimo es de 1 individuo y su representación anatómica corresponde generalmente a huesos del autopodio (fundamentalmente metapodios distales y falanges), con algunas excepciones en donde también se registraron algunos molares sueltos y rótulas ( $c f$. Loponte 2008, 2012). Dado que las falanges y los extremos distales de los metapodios suelen quedar adheridos a los cueros, la presencia de dichos elementos en BR fue interpretada como el resultado del intercambio de pieles que provendrían de los grupos que habitaban el interior de la PO ( $c f$. Loponte 1996-98: 54). También se planteó que el guanaco pudo ser obtenido a través de partidas de caza logísticas desde las bases residenciales localizadas en los BR y en el EIRP hacia la llanura adyacente (PO) (ver detalles en Loponte 1996-98, Loponte 2008, Loponte et al. 2004). Otros autores plantearon una captura de carácter ocasional (Miotti y Tonni 1991). También se debe considerar en forma complementaria al uso de pieles, el aprovechamiento de los metapodios de L. guanicoe con fines tecnológicos, conducta que comienza a detectarse en algunos sitios arqueológicos de los BR como en Arroyo Sarandí (Loponte 2008) y Punta Canal (Arrizurieta et al. 2010b). Por el contrario, en los sitios de la PO, L. guanicoe presenta un NMI mucho más elevado, similar al que posee B. dichotomus en los BR (ver tabla 3).

Los porcentuales MAU (ver figura 2) de las tres especies implicadas sugieren que en ambas áreas no habrían existido diferencias significativas en cuanto a las estrategias de acarreo dentro de cada unidad de paisaje, ya que no se observa una marcada selectividad de partes esqueletarias que indique el transporte diferencial de sus carcasas. Debido a esto, es posible sostener que la mayoría de los individuos de ambas especies fueron cazados y transportados enteros a los loci de consumo final, conducta que también se ve sustentada por la ausencia de covariaciones positivas entre los \% MAU y los índices de utilidad económica (ver tabla 2).

Más allá de las similitudes señaladas, existen otros aspectos que indican una trayectoria diferente de las presas, entre ellos, la contribución económica que, en términos de biomasa, tuvieron los ungulados en relación al resto de los taxones explotados. En la figura 3 podemos ver que la base principal de la subsistencia de los cazadores-recolectores que habitaron la PO fue el guanaco, siendo el venado de las pampas un recurso secundario, como también 


\begin{tabular}{|l|c|c|c|c|}
\hline \multicolumn{1}{|c|}{ Sitio } & \multicolumn{2}{c|}{ Hunter } & \multicolumn{2}{c|}{ Anahí } \\
\hline Variable & L. guanicoe & O. bezoarticus & B. dichotomus & O. bezoarticus \\
\hline NISP & 426 & 104 & 191 & 134 \\
\hline MNE & 203 & 72 & 117 & 105 \\
\hline MNI & 8 & 4 & 6 & \multicolumn{2}{c|}{1799} \\
\hline NISP Mamífero >10kg & \multicolumn{2}{|c|}{439} & \multicolumn{2}{c|}{44,45} \\
\hline \% Biomasa ungulados & \multicolumn{2}{|c|}{94} & & \\
\hline
\end{tabular}

Tabla 3. Representación taxonómica de ungulados en los sitios Hunter (PO) y Anahí (BRM).
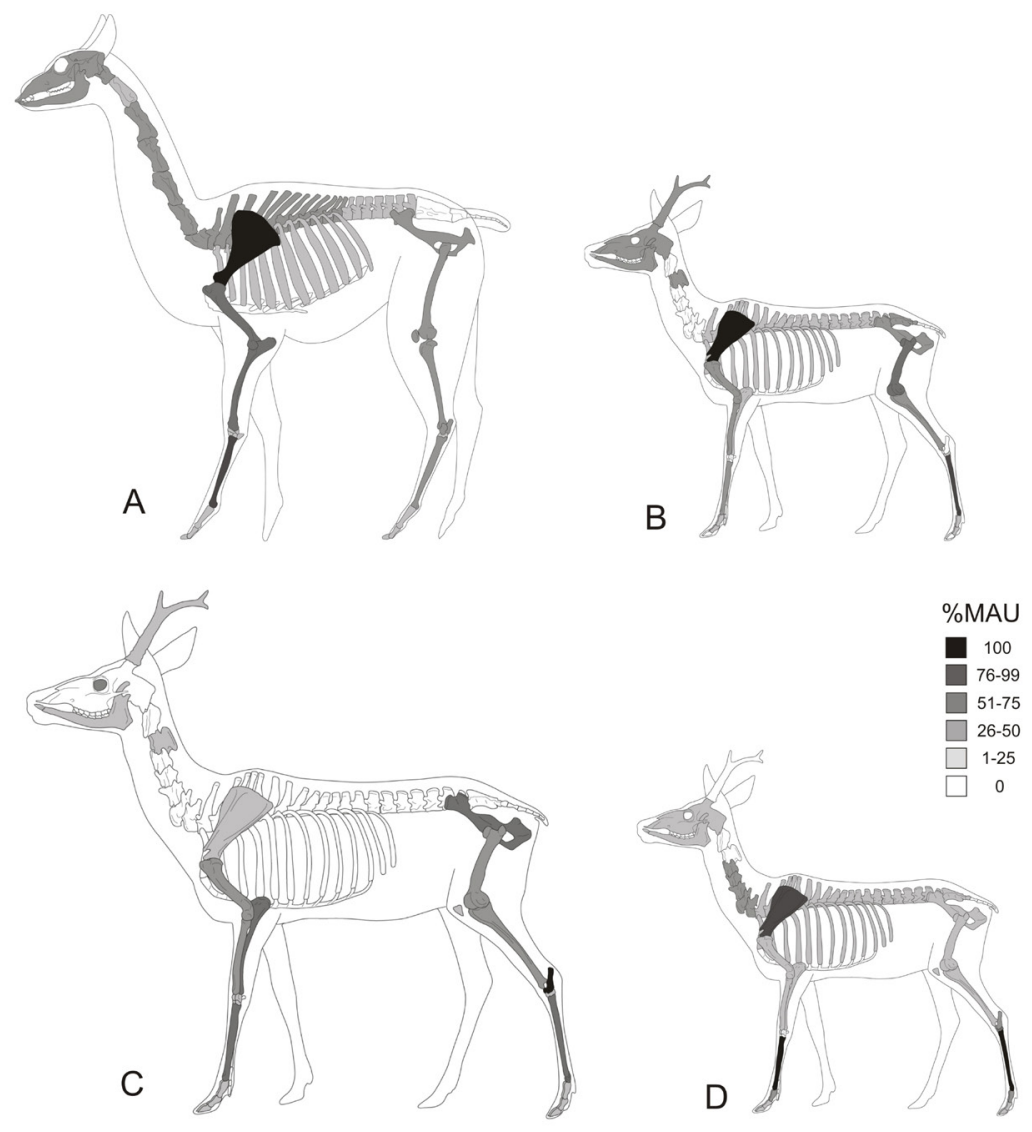

Figura 2. Representación anatómica (\%MAU) en los sitios Hunter y Anahí. Referencias: A). Hunter, L. guanicoe; B) Hunter, O. bezoarticus; C) Anahí, B. dichotomus; D) Anahí, O. bezoarticus.

sucede en otros sitios de la PO (Loponte et al. 2010, Loponte 2012). En los BR, en cambio, $B$. dichotomus y $O$. bezoarticus tuvieron un rol más bien complementario respecto de otros recursos explotados, especialmente los obtenidos a través de la pesca, actividad que adquirió un lugar central en la subsistencia de las sociedades que ocuparon tanto los BR como otros sectores de la cuenca Paraná-Plata durante la fase final del Holoceno reciente (Acosta 2005, Loponte 2008, Musali 2010, Loponte et al. 2012). 

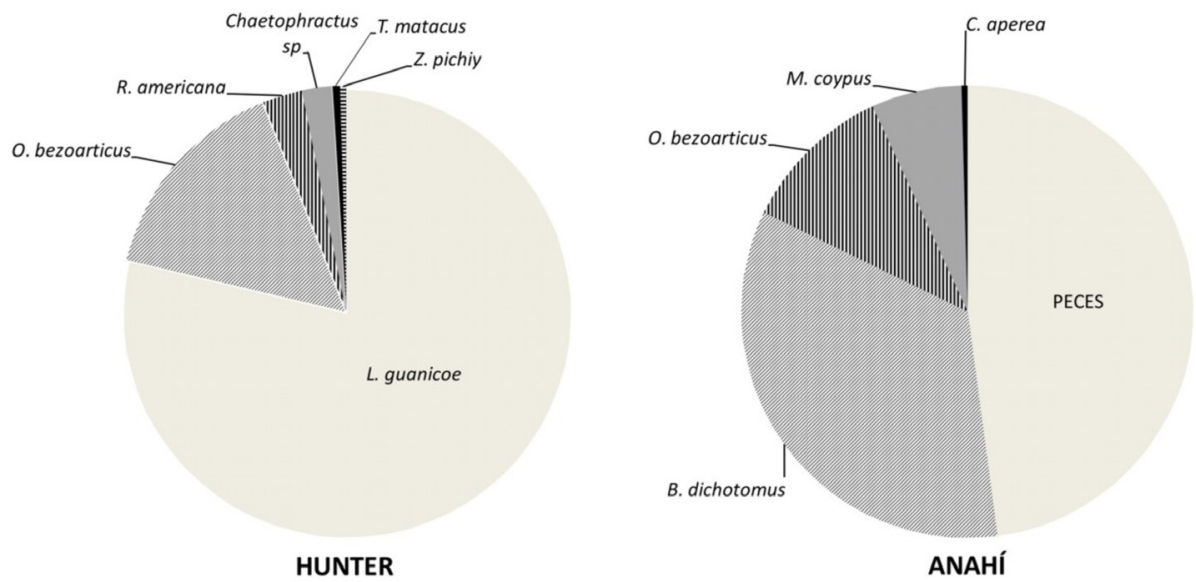

Figura 3. Contribución de biomasa en bruto de las distintas presas en los sitios Hunter y Anahí.

Otras diferencias que pueden apreciarse son las relacionadas con el procesamiento y consumo final de las presas. Si a modo de ejemplo comparamos el índice de completitud anatómica y el MNE estandarizado de L. guanicoe (PO) vs. B. dichotomus (BR) advertimos que el primer taxón presenta valores más elevados que los estimados para el segundo (ver figuras 4 y 5). La baja completitud que poseen los elementos axiales de B. dichotomus respecto de L. guanicoe (ver figura 5) se relacionaría con la integridad diferencial que presentan las vértebras. En tal sentido, mientras que en el primer taxón el estado de estas unidades anatómicas es sumamente fragmentario -lo cual reduce sus niveles de identificación anatómica ${ }^{1}$ en el segundo tienen una mayor integridad, por lo que la relación axial/apendicular observada tiende a ser más cercana a la esperada, situación que también se observa en el caso de O. bezoarticus (ver figura 6). La baja integridad de la columna, que es una tendencia que también se ha verificado en otros sitios de los $\mathrm{BR}$, es un aspecto que no estaría relacionado con procesos tafonómicos (o de transporte diferencial), sino que sería una consecuencia de su fragmentación intencional a fin de maximizar el retorno energético de la región axial (ver discusión en Acosta 2005, Mucciolo 2010).

En cuanto a la fragmentación general de los conjuntos, si se incorporan los especímenes de mamífero (mediano y grande), la cantidad de elementos enteros es mayor en el sitio Hunter (ver tabla 4), lo cual sugiere un menor grado de fragmentación. Sin embargo, aunque este índice es útil como una primera aproximación no permite distinguir hacia qué tipo de tejidos esta orientada la fragmentación, dado que no discrimina entre elementos de diferentes tamaños y valor nutricional. La fragmentación es una propiedad variable en las distintas unidades anatómicas y debe ser medida en función de los recursos internos que brinda cada elemento, razón por la que es esperable que no todos los huesos sean procesados del mismo modo ( $c f$. Binford 1978). Si comparamos las unidades anatómicas que contienen grasa ósea, vemos que la proporción de vértebras completas de L. guanicoe es mayor en Hunter (PO) respecto de la que presenta $B$. dichotomus en el sitio Anahí (BR) (ver tabla 4), característica que también advertimos a partir del índice de completitud anatómica y del MNE estandarizado (figuras 4 y 5). Una tendencia similar se observa en las epífisis de los huesos largos, las cuales 


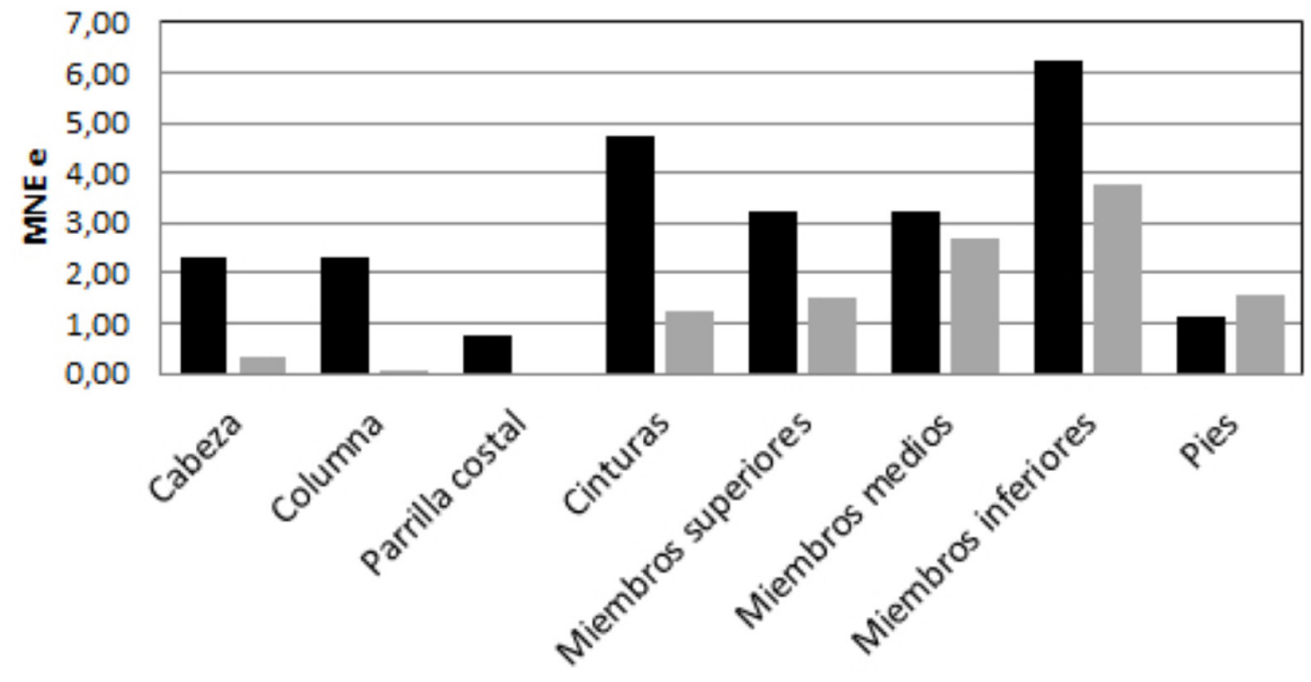

mUNTER L. guanicoe $\square$ ANAHI B. dichotomus

Figura 4. MNE estandarizado por regiones anatómicas L. guanicoe (sitio Hunter) vs. B. dichotomus (sitio Anahí).

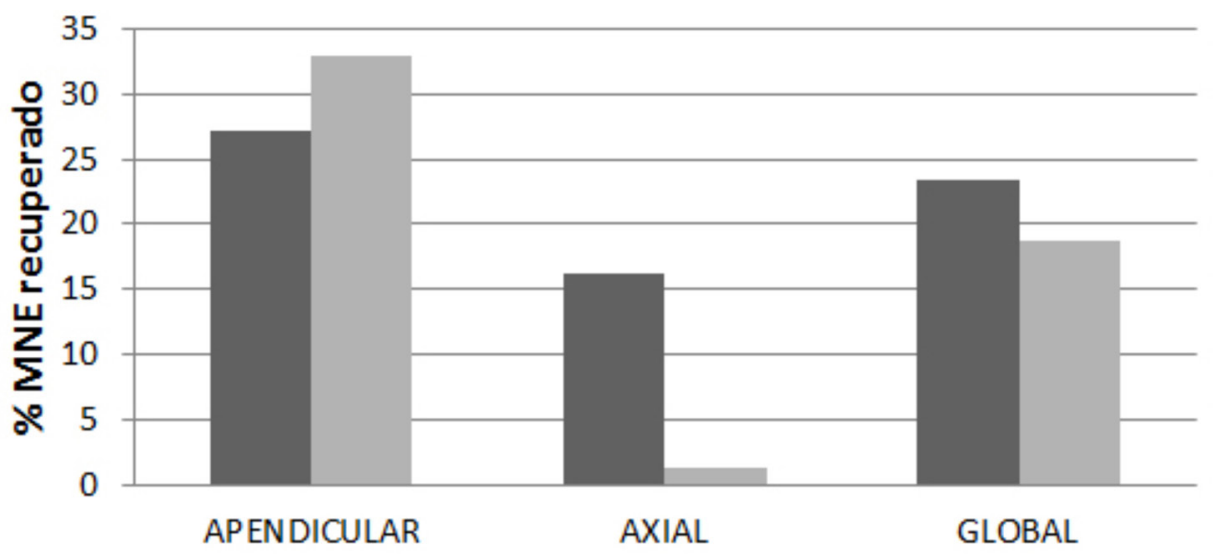

- HUNTER L. guanicoe ANAHI B. dichotomus

Figura 5. Indice de completividad anatómica de L. guanicoe (sitio Hunter) vs. B. dichotomus (sitio Anahí).

también exhiben una mayor completitud en Hunter (L. guanicoe) que en Anahí (B. dichotomus) (tabla 4). La longitud de los especímenes es otra de las propiedades que posibilitan evaluar el grado de procesamiento de la presas, particularmente de sus huesos largos. En la figura 7 vemos que el promedio de longitudes y el tamaño máximo de los restos óseos es más alto en Hunter que en Anahí; lo mismo sucede cuando se comparan los fragmentos de diáfisis asignados a mamífero (mediano y grande, ver figura 8). También hay que destacar que los $\%$ NISP de huesos con negativos de impacto y con huellas de corte son mucho más altos en 


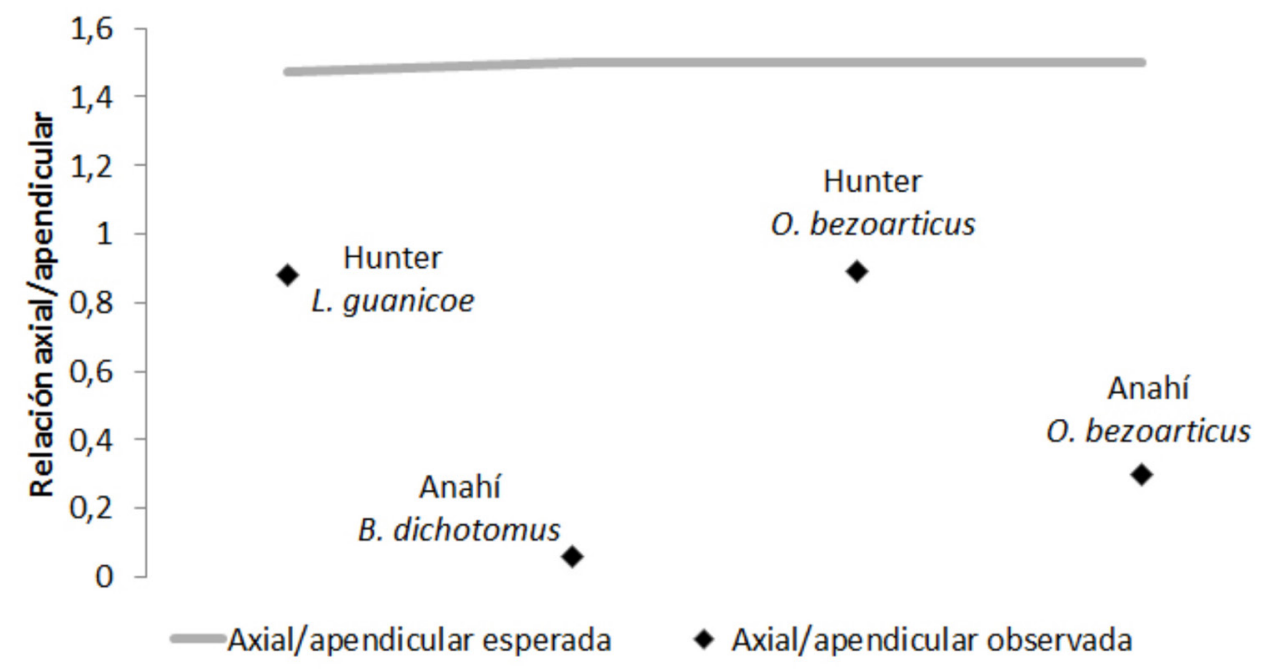

Figura 6. Relación axial/apendicular observada y esperada en los conjuntos de L. guanicoe, B. dichotomus y O. bezoarticus en los sitios Hunter y Anahí.

\begin{tabular}{|l|c|c|c|c|}
\hline \multirow{2}{*}{\multicolumn{1}{|c|}{ Variable }} & \multicolumn{2}{c|}{ Hunter } & \multicolumn{2}{c|}{ Anahí } \\
\cline { 2 - 5 } & L. guanicoe & $\begin{array}{c}\text { O. } \\
\text { bezoarticus }\end{array}$ & $\begin{array}{c}\text { B. } \\
\text { dichotomus }\end{array}$ & $\begin{array}{c}\text { O. } \\
\text { bezoarticus }\end{array}$ \\
\hline Índice de fragmentación de ungulados & \multicolumn{2}{|c|}{3,52} & \multicolumn{2}{c|}{11,01} \\
\hline \% NISP fragmentados & 60,80 & 75,00 & 80,23 & 69,84 \\
\hline \% NISP cuerpos vertebrales completos & 67,69 & 71,43 & 0,00 & 68,80 \\
\hline Índice de fractura fresca (FFI) & 2,69 & 1,85 & 1,40 & 1,65 \\
\hline $\begin{array}{l}\text { Índice de fractura fresca (FFI) incluyendo } \\
\text { mamífero }\end{array}$ & 2,68 & 2,32 & 1,46 & 1,76 \\
\hline \% NISP falange 1 y 2 completas & 27,27 & 83,33 & 4,65 & 28,57 \\
\hline \% NISP falange 3 completas & 100,00 & -- & 75 & 100 \\
\hline \% NISP carpianos + tarsianos completos & 88,24 & 100 & 80,77 & 100 \\
\hline $\begin{array}{l}\text { \% NISP epífisis completas } \\
\text { (sin cuantificar fracturas "modernas") }\end{array}$ & 51,40 & 61,90 & 33,30 & $*$ \\
\hline \% NISP diáfisis con negativos de impacto & 7,52 & 6,98 & 58,6 & 9,6 \\
\hline $\begin{array}{l}\text { \% NISP con huellas de corte } \\
\text { (sin incluir aserrado perimetral) }\end{array}$ & 1,89 & 2,88 & 15,38 & 7,69 \\
\hline
\end{tabular}

Tabla 4. Variables empleadas para evaluar integridad e intensidad de procesamiento en los conjuntos de L. guanicoe, B. dichotomus y O. bezoarticus recuperados en los sitios Hunter y Anahí. * Esta propiedad no fue cuantificada en este conjunto debido a que las epífisis corresponden casi exclusivamente a metapodios distales

Anahí que en Hunter (ver tabla 4). La suma de todos los indicadores mencionados sugiere que el procesamiento de los ungulados habría sido mucho más intensivo en los Bajíos Ribereños que en la Pampa Ondulada.

En relación a los resultados obtenidos a través del índice de fractura fresca (sensu Outram 2001) notamos que en Anahí (BR) los valores obtenidos para B. dichotomus y O. bezoarticus, son consistentes con lo esperado cuando un conjunto presenta una importante proporción de 


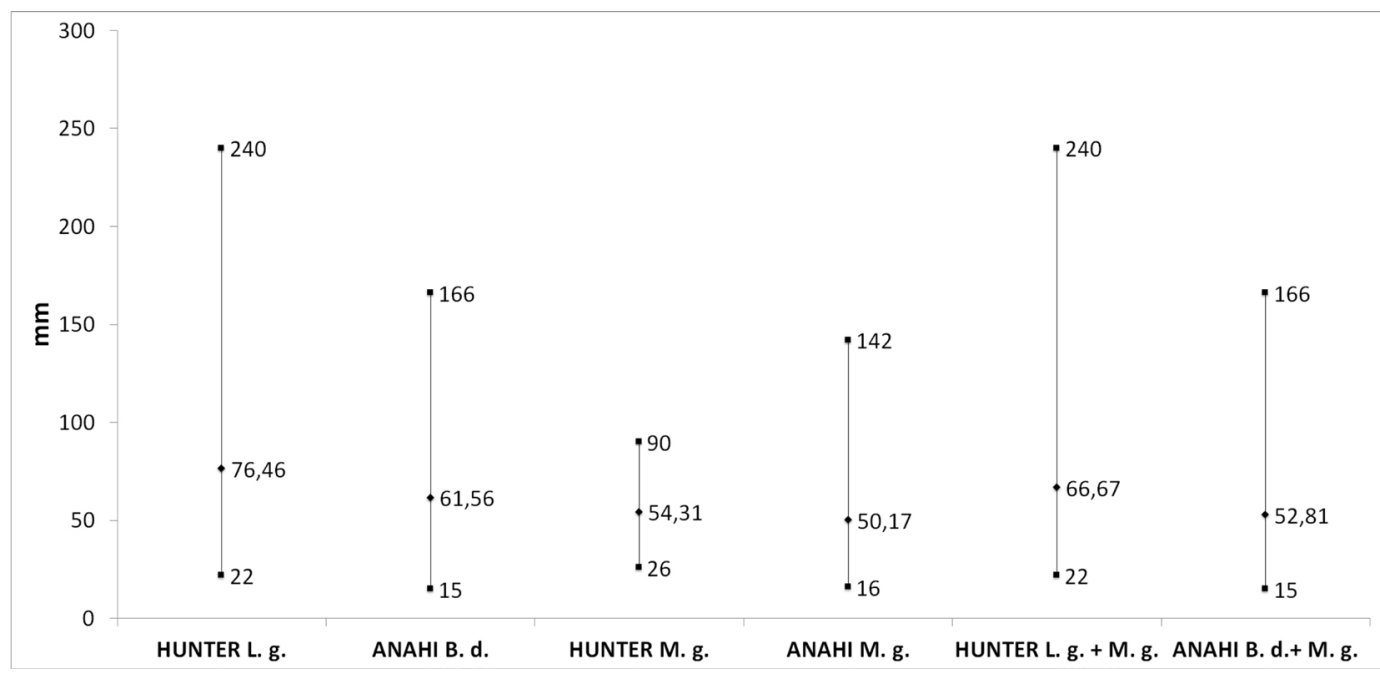

Figura 7. Longitudes máximas, mínimas y promedio de especímenes de huesos largos de ungulados L. guanicoe y $B$. dichotomus y $O$. bezoarticus y de mamíferos (mediano y grande) en los sitios Hunter y Anahí. Referencias: L.g.: L. guanicoe; B. d.: B. dichotomus; M. g.: Mamífero grande.
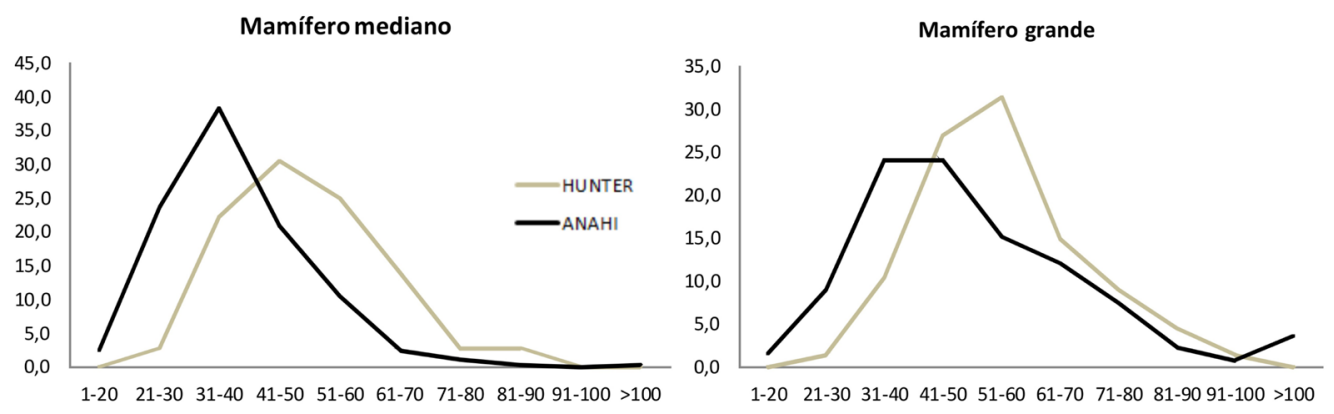

Figura 8. Longitudes de especímenes diafisiarios asignados a la categoría mamífero (mediano y grande).

huesos que fueron fragmentados en estado fresco (ver tabla 4). En cambio, en Hunter (PO) la proporción de especímenes con valores por encima de 2 es mucho más alta, tanto en el caso de los restos asignados a L. guanicoe y O. bezoarticus como los atribuidos a la categoría mamífero (mediano y grande) (ver tabla 4). Esto podría deberse a que la fragmentación observada en Hunter se encuentra parcialmente mediada por procesos post-depositacionales, propiedad que se correlacionaría, como anteriormente señalamos, con una mayor presencia de fracturas en estado seco y con la historia diagenética de los conjuntos óseos. Aun así, como vimos, los integridad anatómica de los ungulados en los BR es mucho más baja que la registrada en la PO.

\section{DISCUSIÓN Y CONCLUSIONES}

El análisis comparativo efectuado indica la existencia de ciertas similitudes y diferencias en torno a las trayectorias conductuales observadas a partir de los conjuntos óseos de 
ungulados generados por los grupos cazadores-recolectores que habitaron el sector centrooriental de la región Pampeana durante el Holoceno tardío. En parte, esta situación se explica por las condiciones ambientales que poseen las microrregiones aquí estudiadas (PO y BR) y por la disponibilidad diferencial vinculada a los requerimientos eto-ecológicos que tienen las distintas especies de ungulados que fueron explotadas. En principio, debe señalarse que la productividad primaria de la PO es mucho más baja que la de BR. Esta última y las demás unidades que integran el paisaje del humedal del Paraná inferior presentan una biodiversidad y riqueza específica (vegetal y animal) sensiblemente más elevada en relación a la que posee la llanura adyacente ( $c f$. Neiff 1999), propiedad que habría condicionado las estrategias de subsistencia de las poblaciones humanas, tal como sucede en otras sociedades de cazadoras-recolectores y regiones del mundo (Kelly 1995, Binford 2001).

En la PO los ungulados, frente a otros recursos disponibles (o explotados), constituyen los de mayor jerarquía, situación que se condice con la contribución diferencial y el grado de dependencia que tuvieron los cazadores-recolectores de estas presas en relación a los demás recursos explotados. También se advierte cierta selectividad ya que, en términos de su NMI y biomasa aportada, L. guanicoe ocupa un lugar central mientras que la contribución de $O$. bezoarticus es visiblemente secundaria. Esta observación también es válida para otros sitios de la PO, como en el caso de Meguay (Loponte et al. 2010, Loponte 2012), y es un hecho recurrente en casi todas las ocupaciones de cazadores-recolectores del Holoceno tardío situadas en otras áreas de la llanura pampeana que comparten, ambiental y arqueológicamente, una biocenosis y una organización económica similar a la registrada en la PO.

En los BR, teniendo en cuenta las características antes mencionadas, es evidente que la oferta natural y la abundancia de los recursos fue sustancialmente distinta a la de PO. El ranking de las presas de los BR indica que los peces constituyeron el macrotaxón mejor posicionado y sobre el cual fue factible ejercer una mayor presión dentro de un proceso de intensificación en la explotación del ambiente ( $c f$. Loponte 2008), relegando a posiciones sucesivamente secundarias tanto a $B$. dichotomus como a O. bezoarticus. Esto explica en parte, la importancia económica de los peces sobre los ungulados que no constituyeron la base principal de la subsistencia de los grupos humanos durante la fase final del Holoceno reciente ( $\leq 2 \mathrm{ka} \mathrm{AP})$, tal como por el contrario, sucedió en la PO.

En relación a la representación diferencial de las presas, pudimos ver que $O$. bezoarticus y L. guanicoe se encuentran arqueológicamente presentes en BR y en la PO; mientras que B. dichotomus solo fue identificada en los BR. En cuanto al primer taxón, su presencia en ambas microrregiones es consistente con su capacidad adaptativa, ya que puede habitar en diferentes ambientes (ver más arriba). Asimismo, su NMI y el hecho de que sus carcasas hayan sido transportadas enteras a las bases residenciales, constituyen evidencia de que fueron capturados dentro de un radio relativamente cercano a los campamentos de los cazadores-recolectores que ocuparon tanto la PO como los BR.

El caso de L. guanicoe es distinto dado que, a pesar de su plasticidad fenotípica y conductual, no habita en zonas bajas e inundables, siendo la estepa uno de los principales ambientes colonizados por esta especie, hecho que no sólo explica su abundante presencia en la PO sino también en otras áreas de la llanura pampeana a lo largo de todo el Holoceno prehispánico (cf. Martínez y Gutiérrez 2004). A su vez, hemos visto que la particular representación (taxonómica y anatómica) que posee L. guanicoe en los BR estaría mediatizada 
por factores culturales básicamente relacionados con el aprovechamiento específico de ciertos productos como pieles y, en menor medida, soportes óseos para la elaboración de artefactos. En los BR estos productos habrían sido obtenidos mediante el intercambio con otros grupos humanos o bien directamente a través de la caza en la llanura adyacente, conductas que pudieron no ser mutuamente excluyentes. La ausencia de $B$. dichotomus en la $\mathrm{PO}$, en términos ecológicos, es un hecho esperable debido a las restringidas y particulares preferencias de hábitat que tiene este taxón (ver más arriba), pero también indica que no se hallaba dentro del radio de acción de los grupos cazadores que ocuparon la PO. Esto se verifica en Hunter y en otros sitios como Meguay y Cañada de Rocha, para los que se dispone de evidencias arqueofaunísticas y de fechados que abarcan los últimos 2000 años C14 AP, momento en el que esta presa (B. dichotomus) ya se encontraba disponible en los BR y en otros sectores del humedal del Paraná inferior.

Sobre la base de los \% MAU y en función de la inexistencia de covariaciones positivas entre estos últimos y los índices de utilidad, sostenemos que las carcasas de las presas de mayor tamaño (B. dichotomus en los BR y L. guanicoe en la PO), al igual que O. bezoarticus, debieron de ingresar enteras a las bases residenciales, siendo difícil establecer si en el lugar de matanza fueron trozadas primariamente con el fin de facilitar su transporte. En la PO el costo de obtención y transporte de L. guanicoe debió ser minimizado a través de una estrategia de mayor movilidad residencial (sensu Binford 1980), comportamiento esperable en un ambiente en donde, a diferencia de los BR, tanto éste como otros recursos explotados se caracterizaron por ser muy móviles y/o estar dispersos en el paisaje (ver Loponte et al. 1991, Loponte 2008).

Hay que destacar que en la PO durante gran parte del Holoceno, ríos como, por ejemplo, el Arrecifes, el Areco y el Luján habrían constituido importantes reservorios de agua. Estos últimos debieron ser parte de los vectores más importantes de movilidad y desplazamiento de las poblaciones humanas, no sólo por la evidente disponibilidad de agua, sino porque, además, la tasa de encuentro con las presas habría sido relativamente más alta que en otros sectores del espacio. Por lo tanto, es posible que la localización de los asentamientos (sensu Jochim 1976) siguiera un patrón lineal a las orillas o muy cerca de los principales cursos hídricos, especialmente en un área que presenta extensas zonas interfluviales que carecen de grandes cuerpos lagunares (Fidalgo 1983). Es esperable que, salvo en una etapa de exploración del ambiente (sensu Borrero 1989-1990), los interfluvios fueran evitados para la instalación de campamentos ya que, además de la falta de agua, no poseían otros recursos (e.g. leña y rocas) que incentivaran su ocupación temporaria o episódica. Esto no implica desestimar la existencia de sitios funcionalmente específicos, de muy baja a nula resolución arqueológica, tales como potenciales lugares de matanza generados durante incursiones de caza realizadas desde las bases residenciales, cercanas a los ríos, hacia el interior de los espacios interfluviales. Dentro de un contexto de alta movilidad residencial también es posible considerar la existencia de rangos de acción extendidos a largas distancias de similares características a los documentados en casos etnográficos ( $c f$. Mac Donald y Hewlett 1999), los cuales habrían posibilitado el acceso directo y abastecimiento de, por ejemplo, rocas y/o bienes exóticos provenientes de otras áreas. En sitios como Hunter y Meguay esta situación se vería corroborada por la presencia de materias primas líticas procedentes de la llanura interserrana y de moluscos marinos típicos de litoral atlántico bonaerense, parte de los cuales fueron reciclados y utilizados como cuentas de collar (cf. Loponte et al. 2010, Tchilinguirian et al. 2011). Desde ya, no debe descartarse que dichos elementos también fueran obtenidos mediante extensas redes de intercambio. 
Una situación diferente se plantea en los BR, aquí los recursos se encuentran muy concentrados y localizados en el espacio y existen diversas líneas de evidencias que indican que los grupos humanos tuvieron una reducida movilidad residencial, asimilable a una estrategia de lugar central o central place foraging, con una estructura de actividades mucho más diversa y compleja que la registrada en los sitios de la PO. Si bien los rangos de acción terrestres pueden conjeturarse que habrían estado dentro de los clásicos 5 a $10 \mathrm{~km}$., el uso de canoas habría posibilitado extender de manera significativa los rangos de forrajeamiento (cf. Loponte 2008, Acosta et al. 2010a). En este contexto, los dispositivos de navegación seguramente constituyeron un medio eficaz para reducir los costos de búsqueda, obtención y transporte de los distintos recursos explotados, hecho que involucraría el traslado e ingreso completo de presas de gran porte como B. dichotomus a las bases residenciales (ver detalles en Acosta 2005, Loponte 2008).

Por otra parte, diversos autores han señalado que la intensidad de procesamiento de la presas depende de distintos factores, entre ellos, la tecnología disponible y el tiempo de permanencia en los asentamientos (Gifford-González 1989, 1993; Kent 1993; Oliver 1993, entre otros). Al respecto, cuando analizamos y comparamos la integridad que presentan los conjuntos óseos de L. guanicoe en la PO y los de B. dichotomus en los BR, notamos ciertas diferencias que podrían estar parcialmente relacionadas con las modalidades que se habrían utilizado durante su procesamiento y consumo final.

Una de las principales diferencias observadas es que B. dichotomus, en relación a L. guanicoe, exhibe en general un mayor grado de fragmentación, rasgo que, a su vez, estaría correlacionado con la baja proporción que presentan los elementos que contienen grasa ósea y con una mayor reducción de sus huesos largos, tal como lo indican las diferencias que presentan ambas especies en cuanto a la longitud y tamaño máximo de los especímenes. Dichas características, en conjunto, indicarían que la intensidad de procesamiento a la que estuvo sometido B. dichotomus fue mayor a la que habría estado expuesto L. guanicoe. En tal sentido, creemos que el gran desarrollo que tuvo la tecnología cerámica en los BR y en casi todo el HPI (e.g. Caggiano 1984, Loponte 2008), frente a la escasa importancia que tuvo en la PO y en otras áreas de llanura pampeana (e.g Madrid 1997), debió incidir de modo significativo en las estrategias vinculadas al procesamiento y consumo de las presas. Se sabe que el uso de contenedores, a través del hervido, posibilita una mayor cantidad de variantes culinarias, maximiza el retorno energético de los alimentos y mejorar su calidad nutricional (Lupo y Schmitt 1997, Wandsnider 1997). El hervido es, además, una técnica eficiente para extraer la grasa ósea, procedimiento que requiere de una mayor fragmentación de los huesos (Kent 1993, Church y Lyman 2001). En síntesis, es posible que la variabilidad observada entre los conjuntos óseos de ambas presas (L. guanicoe vs. B. dichotomus) se encuentre en gran medida relacionada con los factores mencionados y que, en el caso de los BR, el aprovechamiento intensivo de los ungulados y de otros recursos es un hecho íntimamente relacionado con la estabilidad residencial, lo cual es consistente con un modelo o estrategia de lugar central (Loponte 2008, Acosta et al. 2010a).

Las poblaciones cazadoras-recolectoras que poseen una alta dependencia de los recursos acuáticos y vegetales tienden a presentar una movilidad residencial reducida asociada a una mayor compresión demográfica y circunscripción espacial, condiciones bajo las cuales la intensificación de los recursos puede verse como una respuesta ante la disminución de espacios habitables ( $c f$. Binford 2001). Debe señalarse que todos estos aspectos también son compatibles con la emergencia de organizaciones socialmente complejas y que tanto esta 
propiedad como las anteriores han sido analíticamente reconocidas en diversos sitios de cazadores-recolectores que ocuparon los BR y otros sectores del HPI durante el Holoceno tardío (cf. Loponte 2008, Loponte et al. 2006, Acosta et al. 2010b).

En cambio, los grupos humanos que dependen principalmente del consumo de animales terrestres habitan en áreas de mayor amplitud y presentan un menor grado de intensificación (sensu Binford 2001), situación que se ajustaría y explicaría el caso de los cazadores-recolectores que ocuparon la PO. A su vez, es posible que la alta movilidad residencial, que habría caracterizado a estos grupos, haya condicionado o reducido la generación de conductas dependientes de la densidad (Krebs 1995). Esto último, inversamente a lo que habría ocurrido en los BR, pudo implicar la existencia de poblaciones con una baja densidad demográfica y con un menor desarrollo de comportamientos vinculados con el control de los espacios productivos (cf. Kelly 1983) y con la territorialidad (sensu Dyson-Hudson y Smith 1978). Aditivamente, existen distintas crónicas de los siglos XVI y XVII que sugieren la existencia de escasa población aborigen en $\mathrm{PO}$ y otras áreas adyacentes de la región Pampeana (Loponte 2008). Finalmente, es evidente que la incorporación de la PO dentro del panorama arqueológico regional, ha planteado nuevos desafíos e interrogantes, que están siendo explorados concurrentemente con la ampliación de las excavaciones de sitios como Hunter, Meguay y otros depósitos de las cuencas adyacentes. Esto permitirá en el corto plazo aumentar nuestro conocimiento de la variabilidad arqueológica generada por los grupos de cazadores-recolectores que colonizaron las diferentes áreas y ambientes del sector central y norte de la región Pampeana.

Agradecimientos: Queremos agradecer al personal del Museo Municipal de Paleontología y Arqueología de Salto "José F. Bonaparte" (provincia de Buenos Aires), especialmente a su Director José Luis Ramírez, por el apoyo logístico y por la amable colaboración que siempre nos brindaron durante los trabajos de campo efectuados en los sitios Hunter y Meguay. Esta investigación se desarrolló en el marco de los proyectos PICT-FONCYT 2011-2035 y PIP-CONICET 2012-0565. Desde ya, todas las opiniones vertidas en este trabajo son de exclusiva responsabilidad de los autores.

\section{Notas}

1Si bien en el sitio Anahí la representación anatómica de B. dichotomus no incluye vértebras, se identificaron fragmentos de grandes cuerpos vertebrales que pueden pertenecer a este mamífero, pero cuyo estado fragmentario impide una asignación específica (cf. Acosta 2005, Mucciolo 2010).

\section{Bibliografía citada}

Acosta, A.

2005 Zooarqueología de cazadores recolectores del extremo nororiental de la provincia de Buenos Aires (humedal del Paraná inferior, Región Pampeana). Tesis Doctoral inédita. Facultad de Ciencias Naturales y Museo, Universidad Nacional de La Plata. 
Acosta, A.; D. Loponte y L. Mucciolo

2010a Comparando estrategias de explotación faunística en el humedal del Paraná inferior: cazadores-recolectores vs. horticultores amazónicos. Zooarqueología a principios del siglo XXI. Aportes teóricos, metodológicos y casos de estudio (ed. por M. A. Gutiérrez, M. De Nigris, P. M. Fernandez, M. Giardina, A. Gil, A. Izeta, G. Neme y H. Yacobaccio), pp.177-188. Buenos Aires. Acosta, A.; D. Loponte y P. Tchilinguirian

2010b Análisis comparativo sobre la estructura y los procesos de formación de los depósitos arqueológicos en el humedal del Paraná inferior.Arqueología de cazadores recolectores de la cuenca del Plata (compilado por G. Cocco y M.R. Feuillet Terzaghi), pp. 191-208. Centro de Estudios Hispanoamericanos. Santa Fe.

Acosta, A.; L. Mucciolo, J. Musali y M. Arrizurieta

2011 Avances y problemas relacionados con el estudio del registro arqueofaunístico generado por los grupos cazadores-recolectores del extremo sur de la provincia de Entre Ríos (humedal del río Paraná inferior).En: Avances y perspectivas en la Arqueología del NE (ed. por M. R. FeullietTerzaghi, B. Colasurdo, J. Sartori y S. Escudero), pp.: 43-58. ST Servicios Gráficos, Buenos Aires.

Ameghino, F.

1947 [1880] La Antigüedad del Hombre en el Plata. Editorial La Cultura Argentina, Buenos Aires.

Arrizurieta, M. P., L. Mucciolo y J. Musali.

2010a Análisis faunístico preliminar del sitio Cerro Lutz. Mamül Mapu:pasado y presente desde la arqueología pampeana. (ed. por L. Luna, M. Bonomo, C. Montalvo, C. Aranda y M. Carrera, Aizpitarte), tomo 1 pp. 261-276. Editorial Libros del Espinillo. Ayacucho.

Arrizurieta M. P.; N. Buc, B. Mazza, L. Mucciolo, J. Musali, F. Parisi, D. Pau, M. Pérez, M. Poggi y R. Silvestre

2010b Nuevos aportes a la arqueología del sector continental del humedal del Paraná inferior. Arqueología Argentina en el Bicentenario de la Revolución de Mayo (ed. por J. R. Bárcena y H. Chiavaza), Tomo V: 1793-1798. Mendoza.

Behrensmeyer, A. K.

1978 Taphonomic and ecologic information from bone weathering. Paleobiology 4: 150162.

Binford, L. R.

1978. Nunamiut Ethnoarchaeology. Academic Press, New York.

1980 Willow smoke and dog's tails: Hunter-gatherer settlement system and archaeological site formation. American Antiquity 45 (1): 1-17.

1981 Bones: Ancient Men and Modern Myths. Academic Press, New York.

2001 Constructing Frames of Reference. University of California press, Berkeley.

Bonavía, D.

1996 Los Camélidos sudamericanos: una introducción a su estudio. IFEA-UPCH-Conservation International. 843p.

Bonfils, C.

1962 Los suelos del Delta del Río Paraná. Factores generadores, clasificación y uso. Revista de Investigación Agraria VI (3). INTA. Buenos Aires. 
Borrero, L. A.

1989-1990 Evolución cultural divergente en la Patagonia Austral. Anales del Instituto de la Patagonia (Serie Ciencias Sociales) 19: 133-140.

1990 Fuego-Patagonian bone assemblages and the problem of communal guanaco hunting. Hunters of Recent Past (ed. por L. B. Davis y B. O. K. Reeves), pp. 377-399. Unwin Hyman, Londres. Burkart, R., N. Bárbaro, R. Sánchez y D. Gómez

1999 Ecoregiones de la Argentina. Administración de Parques Nacionales. Programa de Desarrollo Institucional Ambiental. Secretaría de Recursos Naturales y Desarrollo Sustentable.

Cabrera, A. L.

1958 Fitogeografía. La Argentina, Suma de Geografía. (ed. por F. de Aparicio y H. A. Difrieri), 3: 101-207.

Cabrera, A. y J. Yepes

1940 Mamíferos Sudamericanos. Editorial EDIAR. Buenos Aires.

Cabrera, A y A. Willink

1980 Biogeografía de América Latina. Organización de Estados Americanos (OEA). Serie Biología. Monografía 3.

Cabrera, L. y E. Zardini

1978 Manual de la Flora de los Alrededores de Buenos Aires. 2a . Edición. Editorial ACME, Buenos Aires.

Caggiano, M. A.

1984 Prehistoria del NE Argentino y sus vinculaciones con la República Oriental del Uruguay y Sur de Brasil. Pesquisas, Antropología 38: 5-109. Instituto Anchietano de Pesquisas, Brasil.

Cavalloto, J.L., R.A. Violante y G. Parker

2004 Sea levels fluctuations during years in the la Plata River (Argentina). Quaternary Internacional, 114 (1): 155-165.

Church, R. R. y R. L. Lyman

2003 Small fragments make small differences in efficiency when rendering grease from fractured artiodactyl bones by boiling. Journal of Archaeological Science 30:1077-1084.

Dalessio S., D. Varela, F. Gagliardi, B. Lartigau, G. Aprile, C. Mónaco y S. Heinomen Fortabat 2001 Ciervo de los pantanos. Los ciervos autóctonos de la Argentina y la acción del hombre (ed. por C. M. Dellafiore y N. Maceira), pp.: 13-26. Secretaría de Desarrollo Sustentable y Política Ambiental. Buenos Aires

Daus, F. 1946. Morfología general de las llanuras argentinas. Geografía de la República Argentina. Sociedad Argentina de Estudios Geográficos 3:115-118.

Dellafiore, C.,A. Vila, A.Parera y N.Maceira 2001. Venado de las pampas. En: Los ciervos autóctonos de la Argentina y la acción del hombre (ed. por C. Dellafiore y N. Maceira), pp.: 83-94. Secretaría de Desarrollo Sustentable y Política Ambiental. Buenos Aires.

De Nigris, M. E.

2004 El consumo en grupos cazadores recolectores: un ejemplo zooarqueológico de Patagonia Meridional. Sociedad Argentina de Antropología, Buenos Aires. 
Duarte, J.M.B., D. Varela, U. Piovezan, M. D. Beccaceci y J.E Garcia

2008 Blastocerus dichotomus.En: IUCN 2011. IUCN Red List of Threatened Species.Version 2011.1.

Dyson-Hudson, R. y E. A. Smith

1978 Human Territoriality: An Ecological Reassessment. American Anthropologist 80: 21-41.

Etchevehere, P. H.

1974 Los suelos. En Carta de suelos de la República Argentina. Hoja 3560-3. Salto. INTA, Instituto suelos. Buenos Aires, Castelar. 81 pag.

Farlow, J. O. y A. Argast

2006. Preservation of fossil bone from the Pipe Creek Sinkhole (Late Neogene, Grant County, Indiana, U.S.A.). Journal of the Paleontological Society of Korea 22 (1): 51-75.

Fidalgo, F.

1983 Algunas características de los sedimentos superficiales en la cuenca del río Salado y en la Pampa Ondulada. Coloquio Internacional de Hidrología sobre Hidrología de Grandes Llanuras. Olavarría. Ms.

Franklin, W.L.

1982. Biology, ecology, and relationship to man of the South American camelids. En: Mammalian Biology in South America (ed. por M. Mares y H. Genoways), pp.:457-488. Pymatuning Laboratory of Ecology.University of Pittsburgh. Special Publication Series, Vol. 6, Pittsburgh.

Gifford-González, D.

1989. Ethnographic Analogues for Interpreting Modified Bones: Some Cases from East Africa. Bone Modification (ed. por R. Bonnichsen y M. Sorg), pp. 179-246. Center for the Study of the First Americans, University of Maine, Orono.

1993. Gaps in Zooarchaeological Analyses of Butchery: Is Gender an Issue?.From Bones to Behavior: Ethnoarchaeological and Experimental Contributions to the Interpretation of Faunal Remains (ed. por J. Hudson), pp. 181-199. Center for Archaeological Investigations, University at Carbondale, Southern Illinois.

Gordon, C. C. y J. E. Buikstra

1981 Soil pH, bone preservation and sampling bias at mortuary sites. American Antiquity 46: 566-571.

Hedges, R. E. M.

2002 Bone diagenesis: an overview of process. Archaeometry 44: 319-328.

Hedges, R. E. M. y A. R. Millard

1995 Bones and groundwater towards the modelling of diagenetic processes, Journal of Archaeological Science22:155-65.

Jochim, M. A.

1976 Hunther-gatherer Subsistence and Settlement: a Predictive Model. Academic Press, New York. 
Kent, S.

1993 Variability in Faunal Assemblages: the Influence of Hunting Skill, Sharing, Dogs and Mode of Cooking on Faunal Remains at a Sedentary Kalahari Community. Journal of Anthropological Archaeology 12: 323-383.

Kelly, R. L.

1983. Hunter-gatherer mobility strategies.Journal of Anthropological Research 39: 277-306.

1995 The Foraging Spectrum. Diversity of Hunter-Gatherer Lifeways. Smithsonian Institution Press, Washington DC.

Krebs, C.

1995. Ecología. Estudio de la Distribución y la Abundancia. Metropolitana. S. A. Iztapalapa, D. F. México.

Lam, Y. M., X. Chen y O. M. Pearson

1999. Intertaxonomic variability in patterns of bone density and the differential representation of bovid, cervid, and equid elements in the archaeological record. American Antiquity 64: 343-362.

Loponte, D. M.

1996-98 Arqueología, etnohistoria y estado sanitario de L. guanicoe (Mammalia, Artiodactyla, Camelidae) en la Pampa Ondulada. Palimpsesto, Revista de Arqueología 5: 41-65.

2008 Arqueología del Humedal del Paraná Inferior (Bajíos Ribereños meridionales). Arqueología de la Cuenca del Plata, Serie Monográfica, editado por A. A. Acosta y D. M. Loponte. Instituto Nacional de Antropología y Pensamiento Latinoamericano, Buenos Aires. 2012. Los extremos de la distribución: la provincia de Misiones y la Pampa Ondulada en la arqueología del nordeste. Anuario de Arqueología. Publicación de las III Jornadas Rosarinas de Arqueología. (ed. por F. Ottalagano y D. Tamburini), Vol. 4, (4): 39-72. Rosario.

Loponte, D., A. Acosta y L. De Santis

1991 Notas preliminares sobre algunos aspectos distributivos del registro arqueológico en el Norte de la provincia de Buenos Aires. Boletín del Centro 2: 7887.

2004. Explotación diferencial de ungulados en el Norte Bonaerense. En: La Región Pampeana, su pasado arqueológico (ed. por C. Gradín y F. Oliva), pp. 355-361. Editorial Laborde, Buenos Aires.

Loponte, D., A. Acosta y J. Musali

2006. Complexity among hunter-gatherers from the Pampean region, South America. En: Beyond Affluent Foragers: Rethinking Hunter-Gatherer Complexity (ed. por C. Grier, J. Kim y J. Uchiyama), pp. 106-125. Oxbow Books, Oxford.

Loponte, D., A. Acosta y P. Tchilinguirian

2010 Avances en la arqueología de la Pampa Ondulada: sitios Hunter y Meguay. En: Arqueología Argentina en el Bicentenario de la Revolución de Mayo (ed. por J. R. Bárcena y H. Chiavaza), Tomo V: 1811-1826. Mendoza.

Loponte, D. y A. Acosta

2012 Nuevos registros de armadillos (Xenarthra; Dasipodidae) del Holoceno Tardío en la Pampa Ondulada. Mastozoología Neotropical 19 (2): 185-206 
Loponte, D; A. Acosta y L. Mucciolo

2012. Contribución a la Arqueología del Delta del Paraná: El Nivel Acerámico del Sitio Isla Lechiguanas 1. Comechingonia 16: 229-268.

Loponte, D. y J. M. Corriale

2012 Isotopic values of diet of Blastocerus dichotomus (marsh deer) in Paraná Basin, South America. Journal of Archaeological Science 40: 1382-1388.

Lothrop, S.

1932 Indians of the Paraná Delta River. Annals of the New York Academy of Sciences XXXIII: 77-232. New York.

Lupo, K. D. y D. N. Schmitt

1997 Experiments in bone boiling: Nutritional returns and archaeological reflections. Anthropozoologica 25/26:137-144.

Lyman, L.

1994. Vertebrate Taphonomy. Cambridge University Press, Cambridge.

Mac Donald, D. H. y B. S. Hewlett

1999 Reproductive Interests and Forager Mobility. Current Anthropology 40 (4): 501-523.

Madrid, $P$.

1997 Análisis petrológicos y alfarería temprana. Arqueología Pampeana en la década de los '90 (ed. por M. Berón y G. Politis), pp. 61-70. INCUAPA, Facultad de Ciencias Sociales. UNCPBA. Olavarría.

Martínez, G. y M. Gutiérrez

2004 Tendencias en la explotación humana de la fauna durante el Pleistoceno Final-Holoceno en la región Pampeana (Argentina). Zooarchaeology of South America (ed. por G. Mengoni Goñalons), pp. 81-98. BAR International Series, Oxford.

Mengoni Goñalons, G. L.

1999 Cazadores de guanacos de la estepa patagónica. Sociedad Argentina de Antropología, Buenos Aires.

Metcalfe, D. y K. Jones

1988 A reconsideration of animal body-part utility index. American Antiquity 53(3): 486-504.

Miotti, L. y E. Tonni

1991 Análisis faunístico preliminar del sitio El Ancla, Punta Indio. Provincia de Buenos Aires. Boletín del Centro 2: 137-150.

Montes, C; D. A. De Lamo y J. Zavatti

2000 Distribución de abundancias de guanacos (Lama guanicoe) en los distintos ambientes de tierra del Fuego, Argentina. Mastozoología Neotropical 7(1): 23-31. 
Mucciolo, L.

2010 Intensidad de procesamiento de cérvidos en el sitio Anahí. En: Mamül Mapu: pasado y presente desde la arqueología pampeana (ed. por M. Berón, L. Luna, M. Bonomo, C. Montalvo, C. Aranda y M. Carrera Aizpitarte), Tomo 1, pp. 335-348. Editorial Libros del Espinillo. Ayacucho, Buenos Aires.

Musali, J.

2010 El rol de la pesca entre los grupos humanos de la baja cuenca del Plata. Ictioarqueología de conjuntos prehispánicos del Holoceno tardío en el humedal del río Paraná inferior. Tesis doctoral inédita. Universidad de Buenos Aires, Facultad de Filosofía y Letras. Buenos Aires.

Neiff, J. J.

1999 El régimen de pulsos en ríos y grandes humedales de Sudamérica. Tópicos sobre Humedales Subtropicales y Templados de Sudamérica (ed. por A. Malvárez), pp. 97-146. Universidad de Buenos Aires, Buenos Aires.

Nielsen-Marsh, C. M. y R. E. M. Hedges

1997 Dissolution experiments on modern and diagenetically altered bone and their effect on the infrared splitting factor, Bulletin de la Société Géologique de France, 168: 485-90.

Nielsen-Marsh, C. M. y R. E. M. Hedges

2000 Patterns of diagenesis in bone I: the effects of site environments. Journal of Archaeological Science 27: 1139-1150.

Oliver, J.S.

1993. Carcass Processing by the Hadza: Bone Breakage from Butchery to Consumption. En: From Bones to Behavior: Ethnoarchaeological and Experimental Contributions to the Interpretation of Faunal Remains (ed. por J. Hudson), pp. 200-227. Center for Archaeological Investigations, University at Carbondale, Southern Illinois.

Outram, A. K.

2001 Anew approach to identifying bone marrow and greaseexploitation: why the "Indeterminate" fragments should not be ignored. Journal of Archaeological Science 28 (4): 401- 410.

Outram, A. K.

2002 Bone fracture and within bone nutrients: an experimentally based method for investigating levels of marrow extraction. Consuming passions and patterns of consumption (ed. por: Preston Miracle y Nicky Milner), pp. 51-64. McDonald Institute for Archaeological Research, Cambridge.

Paleo, M.C., Páez, M. y M. Pérez Meroni.

2002. Condiciones ambientales y ocupación humana durante el Holoceno tardío en el litoral fluvial bonaerense. En Del Mar a los Salitrales. (ed. M. Berón, D, Mazanti y F. Oliva), pp: 365-376. Universidad de Mar del Plata.

Paleo, M.C. y M. Pérez Meroni

2007 Primeros resultados del Sitio “Las Marías" Partido de Magdalena, Provincia de Buenos Aires- En: Arqueología Argentina en los Inicios de un Nuevo Siglo, (compilado por F. Oliva, N. De Grandis y J Rodríguez), pp. 275-283. Universidad Nacional de Rosario. Laborde Editor. 
Parera, A. y D. Moreno

2000 El Venado de las Pampas en Corrientes, diagnóstico de su estado de conservación y propuestas de manejo: Situación crítica. Publicación especial de la Fundación Vida Silvestre Argentina. Buenos Aires.

Parker, R. B. y H. Toots

1970 Minor elements in fossil bone. Geological Society of America Bulletin 81: 925-932.

Pinder, L. y A. Grosse

1991 Blastocerus dichotomus. Mammalian Species 380: 1-4.

Redford, K. H. y J. F. Eisenberg

1992. Mammals of the Neotropics. The Southern Cone. Volume 2. The University of Chicago Press. Chicago, USA, pp.: 234-235.

Silva, M. P. y R. Mauro

2002 Utilización de pasturas nativas por mamíferos herbívoros en el Pantanal. Archivos de Zootecnia, Vol. 51 (193-194): 161- 173, Universidad de Córdoba. España. Córdoba, España.

Stahl, P. H.

1999 Structural Density of Domesticated South American Camelid Skeletal Elements and the Archaeological Investigation of Prehistoric Andean Ch'arki. Journal of Archaeological Science 26: 1347-1368

Stiner, M. C.

1994 Honor among thieves. Princeton University Press. Princeton.

Tchilinguirian, P.; D. Loponte y A. Acosta

2011 Geoarqueología de los sitios Hunter y Meguay, Pampa Ondulada, provincia de Buenos Aires. Cuadernos del Instituto Nacional de Antropología y Pensamiento Latinoamericano. En prensa.

Toledo, M.

2010 Geoarchaeology of the Pleistocene-Holocene transition in NE Pampas: evidence of human presence prior to 13,000 BP, Buenos Aires, Argentina. En: III Simposio Internacional El Hombre temprano en América, (ed. por C. Jiménez, J. Serrano Sánchez, A. González-González y F.J. Aguilar), pp. 205-238. UNAM, Instituto Nacional de Antropología e Historia (INAH) y Museo del Desierto, México.

Voorhies, $M$.

1969 Taphonomy and population dynamics of an early Pliocene vertebrate fauna, Knox County, Nebraska.University of Wyoming Contributions to Geology Special Paper 1, Laramie, 69 pp.

Wandsnider, L.

1997 The Roasted and the Boiled: Food Composition and Heat Treatment with Special Emphasis on Pit-Hearth Cooking. Journal of Anthropological Archaeology 16:1-48

Weber, M. y S. González

2003 Latin American deer diversity and conservation: A review on status and distributions. Ecoscience 10: 443-454. 